\title{
Policy Document on Program Development, Review and Enhancement in Higher Quality Accredited Institutions
}

\author{
Christo Ananth ${ }^{1}$ \\ ${ }^{1}$ College of Engineering, AMA International University, Kingdom of Bahrain
}

Abstract- This Policy Document gives rules to leading Program plan, Development, Review and Enhancement. It covers the means in the plan and improvement, audit and upgrade of all the curricular contributions of the Higher Quality Accredited Institutions.

Keywords- Higher Quality Accredited Institutions, Program Development, Program Review, Program Enhancement, Program Intended Learning Outcomes.

I. INTRODUCTION

Program Development is the way toward thinking of new projects to be advertised. Program Review is the way toward assessing the program as far as its coordinating with the business needs, utilizing contributions from the partner, Program Industry Advisory Panel, and so forth Program Enhancement is the way toward doing a few amendments in the program itself. Scholastic Council underwrite new/overhauled program to the Curriculum Oversight Committee and whenever affirmed by the chamber, submits to the University President for conclusive endorsement. School Council affirms new/reconsidered program in the school and embrace to Academic Council for Curriculum Oversight Committee survey. School Curriculum Review Committee is dependable on the improvement of another program or on the lead of updating a current program in the school. Educational program Oversight Committee as an affirmation board in charge of the survey of the proposed/reconsidered program according to necessity of National Qualification Framework. Partners comprise of industry specialists, graduated class, and officials of expert association whose specialization is adjusted to the proposed new/reexamined programs.

\section{PROCEDURES FOR PROGRAM DEVELOPMENT}

\section{A. BENCHMARKING \& RESEARCH}

The College Curriculum Review Committee (CRC) evaluates the requirement for any new program based on the accompanying: potential interest of the work showcase; rivalry with neighborhood, provincial and other worldwide colleges; forthcoming understudy interests; The accompanying information are accumulated and broke down to guarantee the profundity and broadness of educational plan which will be created: (1) Latest ideas, patterns and application needs of the business, (2) Curricula of driving nearby, territorial and global Universities. Norms required by the Higher Education Body and the gauges of any authorizing body is being considered for the program accreditation. (for example universal gauges set by International Accrediting Organization).

\section{B. PROPOSAL FOR CURRICULUM DEVELOPMENT}

The Curriculum Review Committee readies a proposition for improvement of new curricular program consolidating the consequences of statistical surveying, scholastic benchmarking, and consultative gatherings with inner (staff specialists and understudy 
Christo Ananth et al., International Journal of Advanced Research in Innovative Discoveries in Engineering and Applications[IJARIDEA]

Vol.3, Issue 2, 27 April 2018,pg. 73-77

agents) and outer partners. The total proposition is presented by the Dean to the Academic Council. The Academic Council advances the proposition to the Curriculum Oversight Committee for their remarks or suggestions. On the off chance that the Curriculum Oversight Committee has suggestions, the proposition will be submitted back to the Curriculum Review Committee by means of the Dean for update. If not, the Curriculum Oversight Committee underwrites the proposition to the Academic Council for the University President's Final endorsement. The proposition for new program ought to incorporate the accompanying: Proposed New Program title, Proposed Effectivity Date, Rationale for Development of the Program, Program Description, Target Market, Equipment Requirements, Facilities Requirements, Faculty Requirement, Financial Considerations

\section{ENDORSEMENT AND APPROVAL OF PROPOSAL}

The Curriculum Review Committee through the Dean presents the proposition of the new program to the Academic Council. The Academic Council supports the proposition to the Curriculum Oversight Committee. The Curriculum Oversight Committee will audit the proposed new program and present their acclamations and proposals to the Academic Council. On the off chance that amendments are required, the proposition will be returned back to the Curriculum Review Committee through the Dean. If not, the proposition will be embraced to the Academic Council who will look for its last endorsement from the University President. The University President supports or opposes proposed advancement. In the event that the proposition is objected, it will be come back to the Curriculum Review Committee with the reasons of dissatisfaction. The Curriculum Review Committee may alter the proposition for conceivable re-accommodation. In the event that the proposition is affirmed, the program will be supported for Board of Teachers endorsement and once affirmed, the College will execute the new program as needs be.

\section{PROCESS OF CURRICULUM DEVELOPMENT}

The Curriculum Review Committee in counsel with the College readies the underlying draft of the program detail with the accompanying substance: Program Title, Program Aims, Program Intended Learning Outcomes, Teaching and Learning Methods, Assessment Methods, Curricular Structure, Curriculum Summary, Course Descriptions, Personal and Development Training, Admission Criteria, Program Resources, Curriculum Skills Map. The Curriculum Review Committee sets meeting with the various partners both inner and outside to show the underlying draft of the changed educational plan. Inner partners incorporate understudies and Faculty specialists while outer partners incorporate Alumni and Program Industry Advisory Panel. The Curriculum Review Committee requests criticism from the inward and outer partners on significance and responsiveness of the program points, program expected learning results, educating and learning strategies, appraisal and assessment techniques and rundown of courses. The Curriculum Review Committee solidifies and assesses suggestions given by the inside and outside partners. The last draft of the program determination is displayed to every one of the partners for definite survey and endorsement.

\section{E. IMPLEMENTATION OF NEW PROGRAM}

The Office of the Overall Academic Dean gives duplicate of the new educational program to the: University Registrar who will encourage the handling of proper endorsements and issuance of comparing licenses from the Higher Education Body; University Library for the securing of the required books and perusing materials; Head of Human Resource Development for the employing of suitably qualified Faculty; Head of Accounting Department for the readiness of understudy charges; College Dean, for the encoding of the program to the Course Information framework; to the head of instructional materials and 
Christo Ananth et al., International Journal of Advanced Research in Innovative Discoveries in Engineering and Applications[IJARIDEA]

Vol.3, Issue 2, 27 April 2018,pg. 73-77

production for incorporation to every single Academic distribution and lists of the University. For the new educational plan offering, the University Registration presents the accompanying to Higher Education Body: Application letter mentioning for the authorizing of another program to the General Secretariat of the Higher Education Body at the most recent, Program particular, Rationale for offering the program and the anticipated nearby and local requests for alumni of the program, List of the program asset prerequisites including the important framework, different instructive assets, fittingly qualified Faculty. Endless supply of the positive goals or notice of acknowledgment and endorsement from the Higher Education Body, The University will execute the new program.

\section{PROCEDURES FOR PROGRAM REVIEW AND ENHANCEMENT}

Program audit pursues a 3-multi year cycle whereby potential changes in educational plan, Intended Learning Outcomes, and a few parts of instructing, learning and appraisal can be inspected and assessed. These is to keep up collaboration and significance of alumni ascribes to the present requests/prerequisites of the work advertise.

\section{A. BENCHMARKING \& RESEARCH}

The College Curriculum Review Committee surveys the requirement for an upgrade/update of the current projects based on the accompanying: potential interest of the work showcase; rivalry with neighborhood, territorial and other global colleges; planned understudy premiums; asset necessities; budgetary contemplations; and program proposed learning results and/or understudy results characterized by perceived authorizing bodies. The accompanying information are assembled and investigated to guarantee the profundity and broadness of educational plan which will be created or improved: Latest ideas, patterns and application needs of the business, Curricula of driving neighborhood, provincial and worldwide Universities, Standards required by the Higher Education Body and the guidelines of any authorizing body being considered for the program accreditation.

\section{B. PROPOSAL FOR CURRICULUM DEVELOPMENT}

The College Curriculum Review Committee readies a proposition for correction of existing project fusing the aftereffects of statistical surveying, scholarly benchmarking, and consultative gatherings with inside (personnel specialists and understudy delegates) and outside partners (Program Industry Advisory Panel which speaks to graduated class, business and expert association). The proposition for the modified program ought to incorporate the accompanying: Proposed Revised Program title, Proposed Effectivity Date, Rationale for Revision of the Program, Program Description, Target Market, Equipment Requirements, Facilities Requirements, Faculty Requirement, Financial Considerations, Rationale for the proposed modification/upgrade, Summary of proposed changes in the educational plan (for example Program title, program points, Program Intended Learning Outcomes, and so forth.), Detailed Summary of Changes in Curricular Content, Program Resource Requirement dependent on the proposed update.

\section{ENDORSEMENT AND APPROVAL OF PROPOSAL}

The Curriculum Review Committee through the Dean presents the proposition of the changed program to the Academic Council. The Academic Council supports the proposition to the Curriculum Oversight Committee. The Curriculum Oversight Committee will survey the updated program and present their acclamations and proposals to the Academic Council. On the off chance that modifications are required, the proposition will be returned back to the Curriculum Review Committee by means of the Dean. Whenever affirmed, the proposition will be embraced to the Academic Committee who will look for its last endorsement from the 
Christo Ananth et al., International Journal of Advanced Research in Innovative Discoveries in Engineering and Applications[IJARIDEA]

Vol.3, Issue 2, 27 April 2018,pg. 73-77

University President. The University President favors or opposes proposed improvement. On the off chance that the proposition is objected, it will be come back to the Curriculum Review Committee with the reasons of dissatisfaction. The Curriculum Review Committee may adjust the proposition for conceivable re-accommodation. On the off chance that the proposition is affirmed, the College will execute the improvement/update plan in like manner.

\section{PROCESS OF CURRICULUM DEVELOPMENT}

The College sets meeting with the various partners both inner and outer to recognize holes on the regions of: Curriculum, Efficiency of the Program, Academic Standards of the Graduates, and Quality Assurance and Management. Inner partners incorporate understudies and Faculty specialists while outside partners incorporate Alumni, Employer, External Examiners, and Program Industry Advisory Panel. The College unites and assesses proposals/moves to be made given by the inside and outside partners to address the holes. The College actualizes the suggestions expressed in the Self Evaluation Survey in a joint effort with the Quality Assurance and Administration Office so as to guarantee legitimate usage and checking.

\section{E. IMPLEMENTATION OF REVISED PROGRAM}

The Office of the Vice President for Academic Affairs gives duplicate of the reconsidered educational program to the: University Registrar who will encourage the preparing of proper endorsements and issuance of relating licenses from the Higher Education Body; University Library for the obtaining of the required books and perusing materials; Head of Human Resource and Development for the contracting of suitably qualified Faculty; Head of bookkeeping office for the readiness of understudy expenses; College Dean, for the encoding of the program to the Course Information System; to the head of instructional materials and distribution for incorporation to every single Academic production and lists of the University. For the overhauled educational program offering wherein the scholarly arrangement is essentially changed, the University Registrar presents the accompanying to Higher Education Body: Letter illuminating the HEC regarding the amended educational plan and the proposed date of usage. An official rundown of the progressions made to the educational program. A projection of any advancements foreseen because of the adjustments in the current program including rundown of the program asset prerequisites, for example, vital framework, library and different instructive assets, and fittingly qualified personnel. Endless supply of the positive goals or notice of acknowledgment and endorsement from the Higher Education Body, University will execute the changed program. Quality Records incorporate Labor Market Study, Benchmark Report, Program Specifications, Curriculum Review Enhancement Report, Minutes of the Meetings (Program Industry Advisory Panel, College Curriculum Review Committee, Academic Council, Curriculum Oversight Committee) and Program Review Reports. These records are dispersed to Head, Administration, Overall Academic Dean, Head of Registration, Head of Library, College Deans, Head of IT, Head of Admissions and Head of Quality Assurance and Accreditation

\section{IV. . CONCLUSION}

This Policy Document gives rules to directing Program structure, Development, Review and Enhancement. It covers the means in the plan and advancement, audit and upgrade of all the curricular contributions of the Higher Quality Accredited Institutions. 


\section{REFERENCES}

[1] Department of Education and Skills (2017) Action Plan for Education 2017. Available at: https://www.education.ie/en/Publications/Corporate-Reports/Strategy-Statement/Action-PlanforEducation-2017.pdf

[2] Department of Education and Skills, Ireland (2016) National Skills Strategy 2025. Available at: www.education.ie/en/publications/Policy-Reports/pub_national_skills_strategy_2025 (Accessed: 13th February 2017) European Union High Level Group on Modernisation of Higher Education (2014) New modes of learning and teaching in higher education, Publications Office of the European Union, Luxembourg. Available http://ec.europa.eu/dgs/education_culture/repository/education/library/reports/modernisationuniversitie s_en.pdf

[3] European Union High Level Group on the Modernisation of Higher Education (2013) Improving the quality of teaching and learning in Europe's higher education institutions, Publications Office of the European Union, Luxembourg. Available at: http://ec.europa.eu/dgs/education_culture/repository/education/library/reports/modernisation_e n.pdf

[4] The Irish Survey of Student Engagement (ISSE) (2016) Results from 2016. Available at: http://studentsurvey.ie/wp-content/uploads/2016/11/ISSE-Report-2016-final.pdf

[5] Laurillard, D. (2012) Teaching as a Design Science: Building Pedagogical Patterns for Learning and technology Routledge.

[6] Laurillard, D. (2010) An Approach to Curriculum Design, London Knowledge Lab, Institute of Education, London.

Available at: https://pdfs.semanticscholar.org/b1f6/61ab5e732bfff5fb37c0b76a165d6fc23eeb.pdf

[7] O'Neill, G. (2015). Curriculum Design in Higher Education: Theory to Practice, Dublin: UCD Teaching \& $\quad$ Learning. $\quad$ ISBN $9781905254989 . \quad$ Available at: http://www.ucd.ie/t4cms/UCDTLP0068.pdf

[8] Curriculum Review and Enhancement Process Report Page 33 of 39

[9] O’Neill, G., Donnelly, R. \& Fitzmaurice, M. (2014) Supporting programme teams to develop sequencing in higher education curricula, International Journal for Academic Development, 19:4, 268280

[10] Higher Education Authority, Ireland (2015) National Employer Survey: Employers' Views on Irish Further and Higher Education and Training Outcomes Available at: http://www.hea.ie/sites/default/files/employersurveymay2015final_web_0.pdf

[11] National Forum for the Enhancement of Teaching \& Learning in Higher Education (2015) Teaching and Learning in Irish Education: A Roadmap for Enhancement in a Digital World 2015-2017. Available at: http://www.teachingandlearning.ie/wp-content/uploads/2015/03/Digital-Roadmapweb.pdf 